\title{
Flutter and Thermal Buckling Analysis for Composite Laminated Panel Embedded with Shape Memory Alloy Wires in Supersonic Flow
}

\author{
Chonghui Shao, ${ }^{1}$ Dengqing Cao, ${ }^{1}$ Yuqian Xu, $^{1}$ and Hai $\mathrm{Zhao}^{2}$ \\ ${ }^{1}$ School of Astronautics, Harbin Institute of Technology, P.O. Box 137, Harbin 150001, China \\ ${ }^{2}$ Resource Department, Southwest China Research Institute of Electronic Equipment, Chengdu 610000, China \\ Correspondence should be addressed to Dengqing Cao; dqcao@hit.edu.cn
}

Received 25 July 2016; Accepted 25 September 2016

Academic Editor: Linda L. Vahala

Copyright (c) 2016 Chonghui Shao et al. This is an open access article distributed under the Creative Commons Attribution License, which permits unrestricted use, distribution, and reproduction in any medium, provided the original work is properly cited.

The flutter and thermal buckling behavior of laminated composite panels embedded with shape memory alloy (SMA) wires are studied in this research. The classical plate theory and nonlinear von-Karman strain-displacement relation are employed to investigate the aeroelastic behavior of the smart laminated panel. The thermodynamic behaviors of SMA wires are simulated based on one-dimensional Brinson SMA model. The aerodynamic pressure on the panel is described by the nonlinear piston theory. Nonlinear governing partial differential equations of motion are derived for the panel via the Hamilton principle. The effects of ply angle of the composite panel, SMA layer location and orientation, SMA wires temperature, volume fraction and prestrain on the buckling, flutter boundary, and amplitude of limit cycle oscillation of the panel are analyzed in detail.

\section{Introduction}

Thin panel is a common and useful form of structure component, which has been applied significantly in highspeed vehicles, such as aircraft, spacecrafts, and rockets. Panel flutter, which occurs over a critical velocity under the coupling actions of elastic, inertia, and aerodynamic force induced by the transonic, supersonic, or hypersonic airflow, is one kind of self-excited vibration. Flutter raises the amplitude of vibration as well as the aerodynamic stress dramatically, which results in the failure of the structure. The flutter phenomena were observed on the V-2 rockets for the first time during World War II; since then, lots of studies have been carried out using different structural and aerodynamic theories. Excellent surveys of early researches were presented by Dowell $[1,2]$. Composite materials with the advantages of high strength, light weight, and low coefficient of thermal expansion have been broadly employed in the design of thin-panel structures. Mei et al. [3] presented a recent survey about analytical methods of nonlinear panel flutter in supersonic air flow. Birman and Librescu [4] analyzed aeroelastic instability of laminated composite panels for which the shear deformation is considered in the modeling process under supersonic flow. Kouchakzadeh et al. [5] studied the nonlinear aeroelasticity problem of a laminated composite plate under supersonic airflow, where the classic plate theory was adopted to establish the structure dynamic model, and the supersonic airflow was simulated via linear piston theory. Results obtained in [5] indicated that the ply angle had important influence on the flutter behavior. Zhao and Cao [6] considered the aerodynamic nonlinearity in the modeling process of a stiffened laminate composite panel under supersonic flow. Numerical results in [6] indicated that the position, thickness, and width of the stiffener had significant effect on the aeroelastic behavior.

High-speed aircrafts are subjected to aerodynamic pressure and aerodynamic heating, which should be taken into account when solving the aeroelastic problems. Abbas et al. [7] analyzed the aerothermoelastic behavior of the isotropic and orthotropic panel. Shiau et al. [8] analyzed the influence of temperature gradient on flutter phenomena of a composite 
laminated plate based on the finite element method (FEM). Xie et al. [9] employed the proper orthogonal decomposition (POD) method to analyze the flutter behavior of the panel with uniform thermal loadings. Xue and Mei [10] analyzed aeroelastic problem of the plate under nonuniform thermal loadings by the finite element frequency domain method. Li and Song [11] employed the assumed mode approach and FEM to investigate aerothermoelastic behavior of a composite panel.

In the last two decades, numerous works have been involved in suppressing panel flutter by active or passive control utilizing smart materials. Among these materials, SMA, which is most suitable for active control of composite structures, has been extensively studied. Birman [12] presented a review about various applications of SMA in industry. By heating up to the austenite finish temperature, SMA is able to recover large prestrain totally. SMA can generate large recovery stresses, when the prestrain is restrained. Through embedding SMA in the form of wires within the laminated composites, the recovery stresses can modify stiffness of the structures. This could improve structure characteristics of composite panel such as vibration, thermal bulking, impact loading, flutter, and acoustic. Park et al. [13] employed FEM to study the influences of SMA fibers on flutter and buckling behavior of the plate. Ostachowicz et al. [14] used FEM to analyze the buckling and flutter behaviors of composite plates and the recovery stress generated by SMA fibers embedded in the plate is obtained from experimental data. In accordance with the first-order shear deformation plate theory, Barzegari et al. [15] studied the aeroelastic behavior of rectangular cantilever isotropic wings embedded with SMA wires, where the aerodynamic loading is estimated by linear piston theory. Asadi et al. [16] studied the problem of vibration and thermal buckling for a laminated composite beam in which the SMA fibers are embedded symmetrically and asymmetrically. Kuo et al. [17] used FEM to research flutter behavior of buckled SMA reinforced laminates. The nonlinear aeroelastic behavior of a SMA hybrid composite plate was studied by Ibrahim et al. [18] utilizing a novel FEM.

However, studies mentioned above are focused on thermal buckling and flutter of composite panels embedded with SMA wires employing the FEM without giving consideration to the aerodynamic nonlinearity in the modeling process. Moreover, the well-developed one-dimensional Brinson model for the thermodynamic behaviors of SMA is seldom utilized in the flutter analysis. In this study, in order to analyze the smart laminated panel's dynamic characteristics, the classical plate theory is employed to derive the nonlinear governing differential equations of motion, in which the nonlinear von-Karman strain-displacement relation is adopted. In the modeling process, the thermodynamic behaviors of SMA wires are simulated based on one-dimensional Brinson SMA model, while the aerodynamic pressure is calculated by nonlinear piston theory. The Galerkin method is adopted to derive the system discrete dynamic model, which can be solved numerically by the Runge-Kutta method. The numerical results are utilized to show the effect of SMA wires on the natural frequency, buckling, flutter, and amplitude of limit cycle oscillation (LCO) of a laminated composite panel.

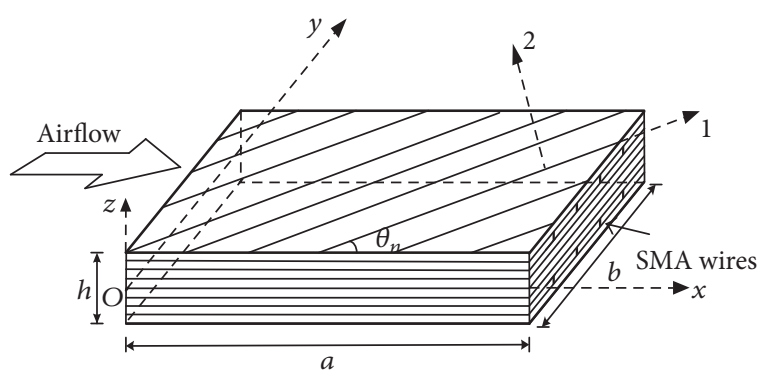

FIgURE 1: Schematic illustration of a smart laminated panel.

\section{Aeroelastic Model}

Consider an 8-layer symmetric composite panel embedded with SMA wires in Cartesian coordinate system with thickness $h$, length $a$, and width $b$ as displayed in Figure 1 . SMA wires are aligned in fiber direction in arbitrary layer. The supersonic flow is along the positive $x$ direction and SMA wires are embedded in the second and seventh layer symmetrically as shown in Figure 1.

2.1. Structure Modeling. The classical plate theory is employed to describe the displacements in the panel; that is,

$$
\begin{aligned}
& u(x, y, z, t)=u_{0}(x, y, t)-z \frac{\partial w_{0}(x, y, t)}{\partial x}, \\
& v(x, y, z, t)=v_{0}(x, y, t)-z \frac{\partial w_{0}(x, y, t)}{\partial y}, \\
& w(x, y, z, t)=w_{0}(x, y, t)
\end{aligned}
$$

where $u, v$, and $w$ denote the displacements in the $x, y$, and $z$ directions, respectively. Subscript " 0 " stands for the midplane displacement. The nonlinear strain-displacement relations, according to the von-Karman assumption, are given by

$$
\left\{\begin{array}{c}
\varepsilon_{x} \\
\varepsilon_{y} \\
\gamma_{x y}
\end{array}\right\}=\left\{\begin{array}{c}
\frac{\partial u_{0}}{\partial x}+\frac{1}{2}\left(\frac{\partial w_{0}}{\partial x}\right)^{2}-z \frac{\partial^{2} w_{0}}{\partial x^{2}} \\
\frac{\partial v_{0}}{\partial y}+\frac{1}{2}\left(\frac{\partial w_{0}}{\partial y}\right)^{2}-z \frac{\partial^{2} w_{0}}{\partial y^{2}} \\
\frac{\partial u_{0}}{\partial y}+\frac{\partial v_{0}}{\partial x}+\frac{\partial w_{0}}{\partial x} \frac{\partial w_{0}}{\partial y}-2 z \frac{\partial^{2} w_{0}}{\partial x \partial y}
\end{array}\right\}
$$

Based on Hooke's law, the constitutive equation of the $n$th layer of the laminated composite panel under thermal loads is

$$
\begin{gathered}
\left\{\begin{array}{c}
\sigma_{x} \\
\sigma_{y} \\
\tau_{x y}
\end{array}\right\}_{(n)}=\mathbf{T}^{-1} \mathbf{Q}_{m(n)} \mathbf{T}^{-T}\left\{\begin{array}{c}
\varepsilon_{x}-\alpha_{x} \Delta T_{(n)} \\
\varepsilon_{y}-\alpha_{y} \Delta T_{(n)} \\
\gamma_{x y}-\alpha_{x y} \Delta T_{(n)}
\end{array}\right\} \\
=\overline{\mathbf{Q}}_{m(n)}\left\{\begin{array}{c}
\varepsilon_{x}-\alpha_{x} \Delta T_{(n)} \\
\varepsilon_{y}-\alpha_{y} \Delta T_{(n)} \\
\gamma_{x y}-\alpha_{x y} \Delta T_{(n)}
\end{array}\right\},
\end{gathered}
$$


where the subscripts " $n$ " and " $m$ " indicate the layer number and the composite matrix, $\Delta T$ denotes the temperature variation, and $\alpha$ stands for the thermal expansion coefficient. The transform matrix $\mathbf{T}$ and stiffness matrix $\mathbf{Q}_{m}$ are defined as [23]

$$
\begin{aligned}
\mathbf{T} & =\left[\begin{array}{ccc}
\cos ^{2} \theta & \sin ^{2} \theta & 2 \sin \theta \cos \theta \\
\sin ^{2} \theta & \cos ^{2} \theta & -2 \sin \theta \cos \theta \\
-\sin \theta \cos \theta & \sin \theta \cos \theta & \cos ^{2} \theta-\sin ^{2} \theta
\end{array}\right], \\
\mathbf{Q}_{m} & =\left[\begin{array}{ccc}
Q_{11 m} & Q_{12 m} & 0 \\
Q_{12 m} & Q_{22 m} & 0 \\
0 & 0 & Q_{66 m}
\end{array}\right],
\end{aligned}
$$

respectively. Here, $Q_{11 m}, Q_{22 m}, Q_{12 m}$, and $Q_{66 m}$ are the stiffness coefficients which are defined as

$$
\begin{aligned}
& Q_{11 m}=\frac{E_{1 m}}{\left(1-v_{12 m} v_{21 m}\right)}, \\
& Q_{22 m}=\frac{E_{2 m}}{\left(1-v_{12 m} v_{21 m}\right)}, \\
& Q_{12 m}=\frac{v_{12 m} E_{2 m}}{\left(1-v_{12 m} v_{21 m}\right)}, \\
& Q_{66 m}=G_{12 m},
\end{aligned}
$$

in which $G_{12 m}, E_{1 m}$, and $E_{2 m}$ stand for the shear modulus and Young modulus and $v_{12 m}$ and $v_{21 m}$ are Poisson ratios.
And for the $k$ th layer of the laminate composite panel embedded with SMA wires, the constitutive equation is as follows [18]:

$$
\begin{aligned}
\{\sigma\}_{(k)}= & \overline{\mathbf{Q}}_{(k)}\{\varepsilon\}+\mathbf{T}^{-1}\left\{\sigma_{r}\right\}_{(k)} V_{s(k)} \\
& -\overline{\mathbf{Q}}_{m(k)}\{\alpha\} \Delta T_{(k)} V_{m(k)},
\end{aligned}
$$

where subscripts " $s$ " and " $k$ " indicate SMA wires and layer number. $\{\sigma\}$ is in-plane stress vectors and $\left\{\sigma_{r}\right\}$, to be described in Section 2.2, is the SMA recovery stress vectors under the temperature T. $\overline{\mathbf{Q}}$ is transformed reduced stiffness matrix of the smart layer. $V$ stands for the volume fractions. The elastic properties used in $\overline{\mathbf{Q}}$ are expressed as

$$
\begin{aligned}
E_{1} & =E_{s} V_{s}+E_{1 m} V_{m}, \\
v_{12} & =v_{s} V_{s}+v_{12 m} V_{m}, \\
E_{2} & =\frac{E_{s} E_{2 m}}{E_{s} V_{m}+E_{2 m} V_{s}}, \\
G_{12} & =\frac{G_{s} G_{12 m}}{G_{s} V_{m}+G_{12 m} V_{s}} .
\end{aligned}
$$

2.2. Description of the Stress Model of SMA Wires. According to one-dimensional model of SMA proposed by Brinson [24] and assuming that all SMA wires are fully constrained, one can get the following expressions for the recovery stress of SMA wires:

$$
\sigma_{r}= \begin{cases}\sigma_{0}+\Theta\left(T-T_{0}\right) & 0 \leq T \leq A_{s}^{\sigma} \\ \sigma_{1}+\left[E_{s}(\xi)-E_{s}\left(\xi_{0}\right)\right] \varepsilon_{0}+\Omega(\xi) \xi_{s}-\Omega\left(\xi_{0}\right) \xi_{s 0}+\Theta\left(T-A_{s}^{\sigma}\right) & A_{s}^{\sigma} \leq T \leq A_{f}^{\sigma} \\ \sigma_{2}+\Theta\left(T-A_{f}^{\sigma}\right) & T \geq A_{f}^{\sigma}\end{cases}
$$

The two constants in (9) are

$$
\begin{aligned}
\sigma_{1}= & \sigma_{0}+\Theta\left(A_{s}^{\sigma}-T_{0}\right), \\
\sigma_{2}= & \sigma_{1}+\left[E_{A}-E_{s}\left(\xi_{0}\right)\right] \varepsilon_{0}+\Omega\left(\xi_{0}\right) \xi_{s 0} \\
& +\Theta\left(A_{f}^{\sigma}-A_{s}^{\sigma}\right) .
\end{aligned}
$$

The phase transformation coefficient $\Omega(\xi)$ and the elastic modulus $E_{s}(\xi)$ have the following expressions:

$$
\begin{aligned}
& \Omega(\xi)=-\varepsilon_{L} E_{s}(\xi), \\
& E_{s}(\xi)=E_{A}+\xi\left(E_{M}-E_{A}\right)
\end{aligned}
$$

The austenite start temperature $A_{s}^{\sigma}$ and finish temperature $A_{f}^{\sigma}$ under stress can be expressed, respectively, as

$$
A_{s}^{\sigma}=\frac{a_{A} A_{s}+b_{A}\left(\Theta T_{0}-\sigma_{0}\right)}{a_{A}+b_{A} \Theta},
$$

$$
\begin{aligned}
& A_{f}^{\sigma} \\
& =\frac{a_{A} A_{s}+\pi-b_{A}\left\{\left[E_{A}-E_{s}\left(\xi_{0}\right)\right] \varepsilon_{0}-\Omega\left(\xi_{0}\right) \xi_{s 0}+\sigma_{0}-\Theta T_{0}\right\}}{a_{A}+b_{A} \Theta},
\end{aligned}
$$

where $\xi$ denotes the martensite fraction, $E_{s}(\xi)$ denotes the elastic modulus of SMA, $\Theta$ represents the thermal elastic modulus, $T$ represents temperature of SMA wires and $T_{0}$ denotes the reference temperature, subscript " 0 " denotes initial conditions, and $\xi_{s}$ stands for the martensite fraction induced by stress. The first expression in (9) is used for SMA in the initial martensite state, the second one is used for SMA in the phase transformation state, and the third one is used for SMA in $100 \%$ austenite state.

The relationships of SMA characteristics transformed from martensite to austenite are given as

$$
\xi=\frac{\xi_{0}}{2}\left\{\cos \left[a_{A}\left(T-A_{s}-\frac{\sigma_{r}}{c_{A}}\right)\right]+1\right\},
$$




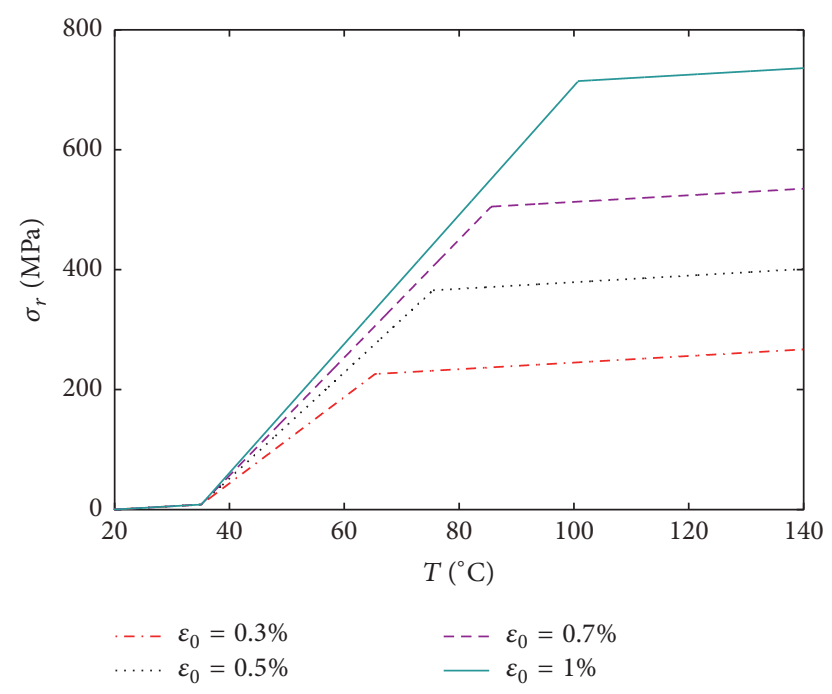

FIgURE 2: Recovery stress generated by SMA.

$$
\begin{aligned}
& \xi_{s}=\xi_{s 0}-\frac{\xi_{s 0}}{\xi_{0}}\left(\xi_{0}-\xi\right), \\
& \xi_{T}=\xi_{T 0}-\frac{\xi_{T 0}}{\xi_{0}}\left(\xi_{0}-\xi\right), \\
& \xi_{0}=\xi_{s 0}+\xi_{T 0}, \\
& a_{A}=\frac{\pi}{A_{f}-A_{s}}, \\
& b_{A}=-\frac{a_{A}}{c_{A}}, \\
& a_{M}=\frac{\pi}{M_{s}-M_{f}}, \\
& b_{M}=-\frac{a_{M}}{c_{M}}
\end{aligned}
$$

where $\xi_{T}$ denotes martensite fraction induced by temperature and $c_{M}$ and $c_{A}$ are phase transformation constants. Figure 2 shows the computed SMA recovery stress versus various temperatures with four prestrain levels. It is shown that, in the phase transformation state, SMA wires can generate large recovery stresses. Moreover, for higher prestrain, an increase in the temperature will generate larger recovery stresses.

2.3. Aerodynamic Pressure Modeling. The aerodynamic load, $\Delta p$, is described by the third-order piston theory as

$$
\begin{aligned}
\Delta p & =\frac{2 q}{M}\left[\frac{\dot{w}_{0}}{v_{\infty}}+\frac{\partial w_{0}}{\partial x}+\frac{(\gamma+1) M}{4}\left(\frac{\dot{w}_{0}}{v_{\infty}}+\frac{\partial w_{0}}{\partial x}\right)^{2}\right. \\
& \left.+\frac{(\gamma+1) M^{2}}{12}\left(\frac{\dot{w}_{0}}{v_{\infty}}+\frac{\partial w_{0}}{\partial x}\right)^{3}\right],
\end{aligned}
$$

where, $\rho_{a}, v_{\infty}, \gamma$, and $M$ denote the density, velocity, ratio of specific heats, and Mach number of airflow and $q=\rho_{a} v_{\infty}^{2} / 2$.
2.4. Governing Equations of Motion. The partial differential equations of motion for the panel can be obtained by utilizing Hamilton principle.

$$
\int_{t_{0}}^{t_{1}}(\delta T+\delta W-\delta U) d t=0
$$

where the variations of kinetic energy $\delta T$ and virtual work $\delta W$ as well as variation of strains energy $\delta U$ are given by

$$
\begin{aligned}
& \delta T=\int_{0}^{b} \int_{0}^{a} \int_{-h / 2}^{h / 2} \rho(\dot{u} \delta \dot{u}+\dot{v} \delta \dot{v}+\dot{w} \delta \dot{w}) d z d x d y, \\
& \delta W=-\int_{0}^{b} \int_{0}^{a} \Delta p \delta w(x, y, 0.5 h) d x d y,
\end{aligned}
$$

$\delta U$

$$
=\int_{0}^{b} \int_{0}^{a} \int_{-h / 2}^{h / 2}\left(\sigma_{x} \delta \varepsilon_{x}+\sigma_{y} \delta \varepsilon_{y}+\tau_{x y} \delta \gamma_{x y}\right) d z d x d y,
$$

where $\rho$ stands for density of the smart laminated panel.

Substituting (1)-(5), (7), (8), and (16) into (15) and setting the coefficients of $\delta u, \delta v$, and $\delta w$ to be zero, one has

$$
\begin{aligned}
& \frac{\partial N_{x x}}{\partial x}+\frac{\partial N_{x y}}{\partial y}=I_{0} \ddot{u}_{0}, \\
& \frac{\partial N_{y y}}{\partial y}+\frac{\partial N_{x y}}{\partial x}=I_{0} \ddot{v}_{0}, \\
& \left(\frac{\partial N_{x x}}{\partial x}+\frac{\partial N_{x y}}{\partial y}\right) \frac{\partial w_{0}}{\partial x}+\left(\frac{\partial N_{y y}}{\partial y}+\frac{\partial N_{x y}}{\partial x}\right) \frac{\partial w_{0}}{\partial y} \\
& \quad+N_{x x} \frac{\partial^{2} w_{0}}{\partial x^{2}}+N_{y y} \frac{\partial^{2} w_{0}}{\partial y^{2}}+2 N_{x y} \frac{\partial^{2} w_{0}}{\partial x \partial y}+\frac{\partial^{2} M_{x x}}{\partial x^{2}} \\
& \quad+\frac{\partial^{2} M_{y y}}{\partial x^{2}}+2 \frac{\partial^{2} M_{x y}}{\partial x \partial y}-\Delta p=I_{0} \ddot{w}_{0} \\
& \quad-I_{2}\left(\frac{\partial^{2} \ddot{w}_{0}}{\partial x^{2}}+\frac{\partial^{2} \ddot{w}_{0}}{\partial y^{2}}\right),
\end{aligned}
$$

where $\left(I_{0}, I_{2}\right)=\int_{-h / 2}^{h / 2} \rho\left(1, z^{2}\right) d z$ and the force resultants operators are obtained as

$$
\begin{aligned}
& {\left[\begin{array}{c}
N_{x x} \\
N_{y y} \\
N_{x y}
\end{array}\right]=\int_{-h / 2}^{h / 2}\left[\begin{array}{c}
\sigma_{x} \\
\sigma_{y} \\
\tau_{x y}
\end{array}\right] d z,} \\
& {\left[\begin{array}{c}
M_{x x} \\
M_{y y} \\
M_{x y}
\end{array}\right]=\int_{-h / 2}^{h / 2}\left[\begin{array}{c}
\sigma_{x} \\
\sigma_{y} \\
\tau_{x y}
\end{array}\right] z d z .}
\end{aligned}
$$


The boundary conditions for a simply supported panel are

$$
\begin{gathered}
\left.u_{0}\right|_{x=0, a}=0, \\
\left.u_{0}\right|_{y=0, b}=0, \\
\left.v_{0}\right|_{x=0, a}=0, \\
\left.v_{0}\right|_{y=0, b}=0, \\
\left.w_{0}\right|_{x=0, a}=0, \\
\left.w_{0}\right|_{y=0, b}=0, \\
\left.\frac{\partial w_{0}^{2}}{\partial x^{2}}\right|_{x=0, a}=0, \\
\left.\frac{\partial w_{0}^{2}}{\partial y^{2}}\right|_{y=0, b}=0 .
\end{gathered}
$$

The displacements of the panel satisfying the boundary conditions are written as follows:

$$
\begin{aligned}
& u_{0}(x, y, t)=\sum_{i=1}^{l} \sum_{j=1}^{m} a_{i j}(t) \Phi_{i j}(x, y), \\
& v_{0}(x, y, t)=\sum_{i=1}^{l} \sum_{j=1}^{m} b_{i j}(t) \Phi_{i j}(x, y), \\
& w_{0}(x, y, t)=\sum_{i=1}^{l} \sum_{j=1}^{m} c_{i j}(t) \Phi_{i j}(x, y),
\end{aligned}
$$

where the mode shapes are taken as

$$
\Phi_{i j}(x, y)=\sin \left(\frac{i \pi x}{a}\right) \sin \left(\frac{j \pi y}{b}\right)
$$

The numerical results provided by Dowell [25] show that for getting reasonable results at least four modes are needed to study the panel flutter behavior. In present study, four streamwise modes and one spanwise mode are reserved in the following calculation. Substituting (20) into (17) and after that integrating over the panel area, the discrete dynamic model is given as

$$
\begin{aligned}
& \ddot{a}_{i}=\frac{4}{a b I_{0}} \int_{0}^{a} \int_{0}^{b}\left(\frac{\partial N_{x x}}{\partial x}+\frac{\partial N_{x y}}{\partial y}\right) \Phi_{i}(x, y) d x d y, \\
& \ddot{b}_{i}=\frac{4}{a b I_{0}} \int_{0}^{a} \int_{0}^{b}\left(\frac{\partial N_{y y}}{\partial y}+\frac{\partial N_{x y}}{\partial x}\right) \Phi_{i}(x, y) d x d y,
\end{aligned}
$$

$$
\begin{aligned}
\ddot{c}_{i} & =\frac{4 a b}{a^{2} b^{2} I_{0}+\left(i^{2} b^{2}+a^{2}\right) \pi^{2} I_{2}} \\
& \cdot \int_{0}^{a} \int_{0}^{b}\left(\left(\frac{\partial N_{x x}}{\partial x}+\frac{\partial N_{x y}}{\partial y}\right) \frac{\partial w_{0}}{\partial x}\right. \\
& +\left(\frac{\partial N_{y y}}{\partial y}+\frac{\partial N_{x y}}{\partial x}\right) \frac{\partial w_{0}}{\partial y}+\frac{\partial^{2} M_{x x}}{\partial x^{2}}+\frac{\partial^{2} M_{y y}}{\partial y^{2}} \\
& +2 \frac{\partial^{2} M_{x y}}{\partial x \partial y}+N_{x x} \frac{\partial^{2} w_{0}}{\partial x^{2}}+N_{y y} \frac{\partial^{2} w_{0}}{\partial y^{2}}+2 N_{x y} \frac{\partial^{2} w_{0}}{\partial x \partial y} \\
& -\Delta p) \Phi_{i}(x, y) d x d y .
\end{aligned}
$$

Let

$$
y=\left\{a_{1}, \dot{a}_{1}, \ldots, a_{4}, \dot{a}_{4}, b_{1}, \dot{b}_{1}, \ldots, b_{4}, \dot{b}_{4}, c_{1}, \dot{c}_{1}, \ldots, c_{4}, \dot{c}_{4}\right\}^{T},
$$

and then (22) can be expressed as

$$
\dot{y}=\mathbf{A} y+g(y),
$$

where $\mathbf{A}$ is the Jacobian matrix at the equilibrium point $y=0$ and $g(y)$ respects the nonlinear terms induced by geometric and aerodynamic nonlinearity.

\section{Results and Discussion}

As the dynamic pressure $\lambda$ reaches the critical flutter dynamic pressure $\lambda_{\mathrm{cr}}$, the motion of the panel changes from flat condition to flutter condition based on the nonlinear theory. If $\lambda>\lambda_{\text {cr }}$, because of the existence of the geometric and aerodynamic nonlinearities, the amplitude of vibration of the panel will increase with time and eventually converge at a limit cycle. On the contrary, the amplitude of vibration will decrease with time if $\lambda<\lambda_{\mathrm{cr}}$. The general solution of (24) can be written as

$$
y(t)=y_{0} e^{\varphi_{j} t}, \quad \varphi_{j}=\alpha_{j} \pm i \beta_{j},
$$

where $y_{0}$ and $\varphi_{j}$ stand for the eigenvector and eigenvalues of the matrix $\mathbf{A}$. The natural frequencies of the panel can be obtained as

$$
\omega_{j}=\sqrt{\beta_{j}^{2}}
$$

As the real part of arbitrary eigenvalue turns from negative to positive, the flutter will happen. By examining the maximal real part of eigenvalues $\mu, \lambda_{\mathrm{cr}}$ can be obtained. $\mu$ can be described as

$$
\mu=\max \left[\operatorname{Re}\left(\varphi_{j}\right)\right]=\max \left(\alpha_{j}\right) .
$$

In the present study, the laminated panel with width of $0.4 \mathrm{~m}$, length of $0.5 \mathrm{~m}$, and thickness of $0.0025 \mathrm{~m}$ is taken for analysis (except Section 3.3 where the effect of length-to-width ratios on $\lambda_{\mathrm{cr}}$ is discussed). The transverse 
displacements are plotted at the point $(x, y)=(0.75 a, 0.5 b)$. The material parameters are given as follows.

Composite Lamina Properties

$$
\begin{aligned}
E_{1 m} & =138 \mathrm{GPa}, \\
E_{2 m} & =9.7 \mathrm{GPa}, \\
G_{12 m} & =5.5 \mathrm{GPa}, \\
\rho_{m} & =1580 \mathrm{~kg} / \mathrm{m}^{3}, \\
v_{m} & =0.3 .
\end{aligned}
$$

SMA Wires Properties

$$
\begin{aligned}
E_{A} & =67 \mathrm{GPa}, \\
E_{M} & =26.3 \mathrm{GPa}, \\
M_{s} & =18.4^{\circ} \mathrm{C}, \\
M_{f} & =9^{\circ} \mathrm{C}, \\
A_{s} & =34.5^{\circ} \mathrm{C}, \\
A_{f} & =49^{\circ} \mathrm{C}, \\
C_{M} & =8 \mathrm{MPa} /{ }^{\circ} \mathrm{C}, \\
C_{A} & =13.8 \mathrm{MPa} /{ }^{\circ} \mathrm{C}, \\
\Theta & =0.55, \\
\varepsilon_{l} & =0.067, \\
\sigma_{0} & =0, \\
T_{0} & =20^{\circ} \mathrm{C}, \\
\rho_{s} & =6450 \mathrm{~kg} / \mathrm{m}^{3}, \\
\xi_{T 0} & =0, \\
v_{s} & =0.33 .
\end{aligned}
$$

3.1. Validations of the Present Method. The numerical calculations are performed via MATLAB software. Based on the derived formulation, the Runge-Kutta method is utilized to investigate nonlinear flutter and buckling behavior of isotropic panel and laminated composite panel, respectively. The critical thermal buckling temperature is compared with the results provided by Matsunaga [22], Zhao et al. [19], Shiau et al. [20], and Shi et al. [21]. Tables 1 and 2 list the results of the former analyses and the present works. It can be observed from Tables 1 and 2 that the results obtained here have a good agreement with those results in the literature. In addition, the amplitude of LCO of the panel with thermal effect obtained here has a good agreement with those results in [26] as shown in Figure 3.

3.2. The Effects of Orientation and Position of Layer Embedded with SMA Wires. The influences of orientation of SMA wires
TABLE 1: Critical buckling temperature of the isotropic panel.

\begin{tabular}{lcccc}
\hline & Zhao et al. [19] & Shiau et al. [20] & Shi et al. [21] & Present \\
\hline$\Delta T_{\mathrm{cr}}\left({ }^{\circ} \mathrm{C}\right)$ & 126.5 & 127.1 & 126.4 & 126.43 \\
\hline
\end{tabular}

TABLE 2: Comparison of critical buckling temperature for composite panel.

\begin{tabular}{lcc}
\hline Ply angle & \multicolumn{2}{c}{$\Delta T_{\text {cr }}\left({ }^{\circ} \mathrm{C}\right)$} \\
& Matsunaga $[22]$ & Present \\
\hline$[0 / 90 / 90 / 0]_{s}$ & 6.8 & 6.79 \\
{$[0 / 45 /-45 / 90]_{s}$} & 7.6 & 7.59 \\
\hline
\end{tabular}

on $\lambda_{\text {cr }}$ are investigated first. The fiber orientation of the composite panel is assumed to be $\left[90 /-45 / 45 / \theta^{\mathrm{SMA}}\right]_{s}$ with SMA wires embedded in the fourth and fifth layer symmetrically. The SMA wires have prestrain of $0.5 \%$, volume fraction of $1 \%$, and temperature of $50^{\circ} \mathrm{C}$. The variation of $\lambda_{\mathrm{cr}}$ versus the angle of SMA wires is depicted in Figure 4. It can be observed from Figure 4 that changing the angle of layer embedded with SMA wires from $0^{\circ}$ to $90^{\circ}$ decreases $\lambda_{\text {cr }}$ of the panel. Also, it is shown that the panel has the highest $\lambda_{\text {cr }}$ with the ply angle of $\left[90 /-45 / 45 / 0^{\mathrm{SMA}}\right]_{s}$. Consequently, orientation of the layer embedded with SMA wires is the most important parameters for designing and optimizing the smart laminated panel. In the following analysis, the orientation of layer embedded with SMA wires is designed to be zero.

As for the influences of position of the layer embedded with SMA wires of the 8-layer symmetric laminated panel on the $\lambda_{\text {cr }}$ change, it is found in Figure 5 that five cases of laminated panels with different position of the layer embedded with SMA wires have been studied. From Figure 5 one can see that when changing the positon of the layer embedded with SMA wires from outer layer $\left[0^{\mathrm{SMA}} /-60 / 60 /-60\right]_{s}$ to inner layer $\left[60 /-60 / 60 / 0^{\mathrm{SMA}}\right]_{s}$ in sequence, $\lambda_{\mathrm{cr}}$ may decrease, which indicates that embedding SMA wires in the outer layer is more significant for enhancing $\lambda_{\mathrm{cr}}$ of the laminated panel.

3.3. The Effects of Length-to-Width Ratios. Figure 6 shows the flutter boundary versus fiber orientation $[\theta /-\theta / \theta /-\theta]_{s}$ under different length-to-width ratios of the panel. For the case when $a / b \leq 2$, increasing the fiber orientation from $0^{\circ}$ to $90^{\circ}$ results in decreasing the stiffness of the panel in the $x$ direction, which will lower the flutter boundary of the panel. However, for the case when $a / b>2, \lambda_{\text {cr }}$ increases as $\theta$ increases initially and decreases afterwards. In addition, Figure 6 reveals that an increase in the panel length-to-width ratios leads to a stiffer composite panel.

3.4. The Effects of Thermal Loads. The curves of frequencies $\omega$ versus $\lambda$ for the panel without SMA wires under different temperature variation are shown in Figure 7 . It can be found in Figure 7 that as the dynamic pressures increasing the first and the second natural frequencies gradually approach each other and finally overlap, then the panel will be in a limit cycle oscillation condition. Also, the natural frequencies and 


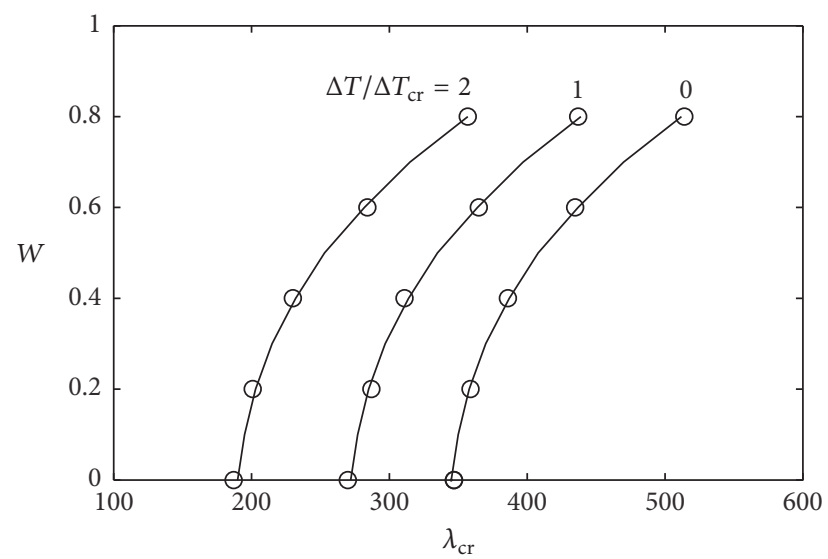

Present

Xue and Mei [26]

Figure 3: Comparison of limit cycle amplitudes.

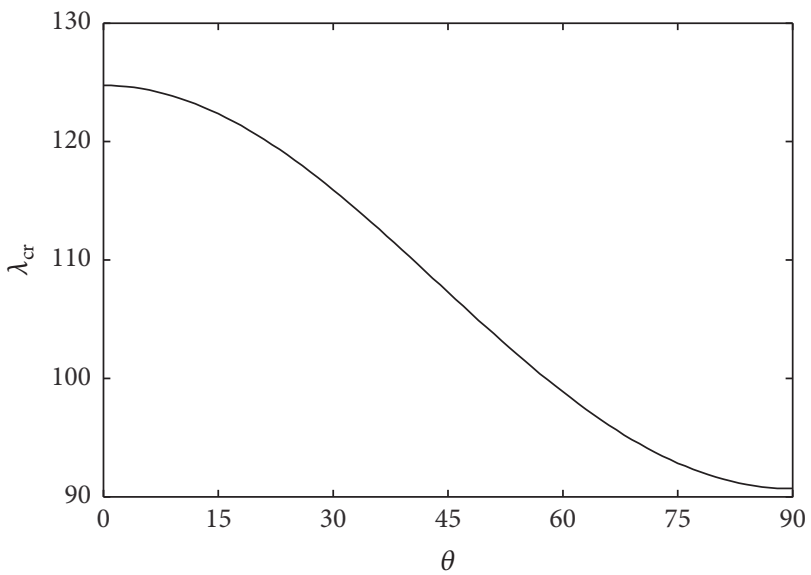

FIGURE 4: Flutter boundary versus orientation angles of SMA wires.

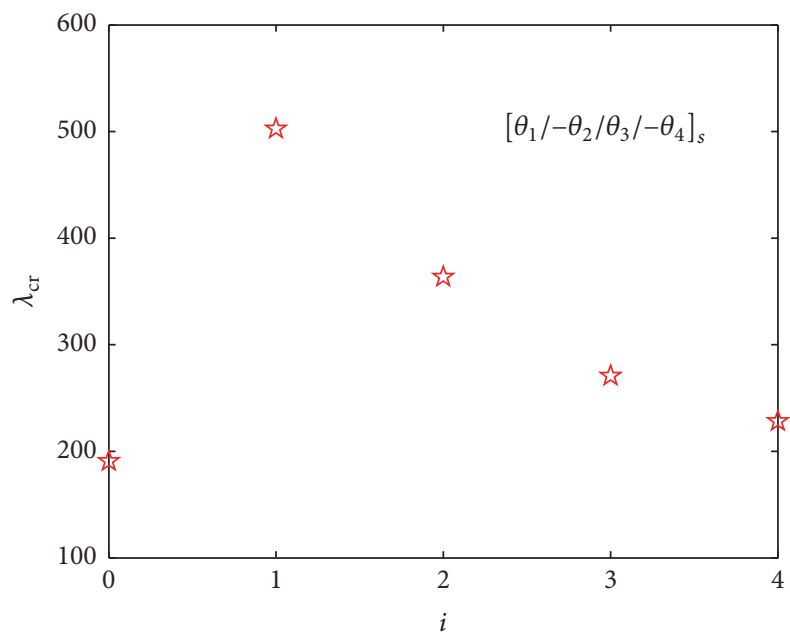

FIGURE 5: Flutter boundary versus position of layer embedded with SMA wires $\left(i=0,[60 /-60 / 60 /-60]_{s} ; i=1,\left[0^{\mathrm{SMA}} /-60 / 60 /-60\right]_{s}\right.$; $i=2,\left[60 / 0^{\mathrm{SMA}} / 60 /-60\right]_{S} ; i=3,\left[60 /-60 / 0^{\mathrm{SMA}} /-60\right]_{s} ; i=4$, $\left[60 /-60 / 60 / 0^{\mathrm{SMA}}\right]_{s}$.).

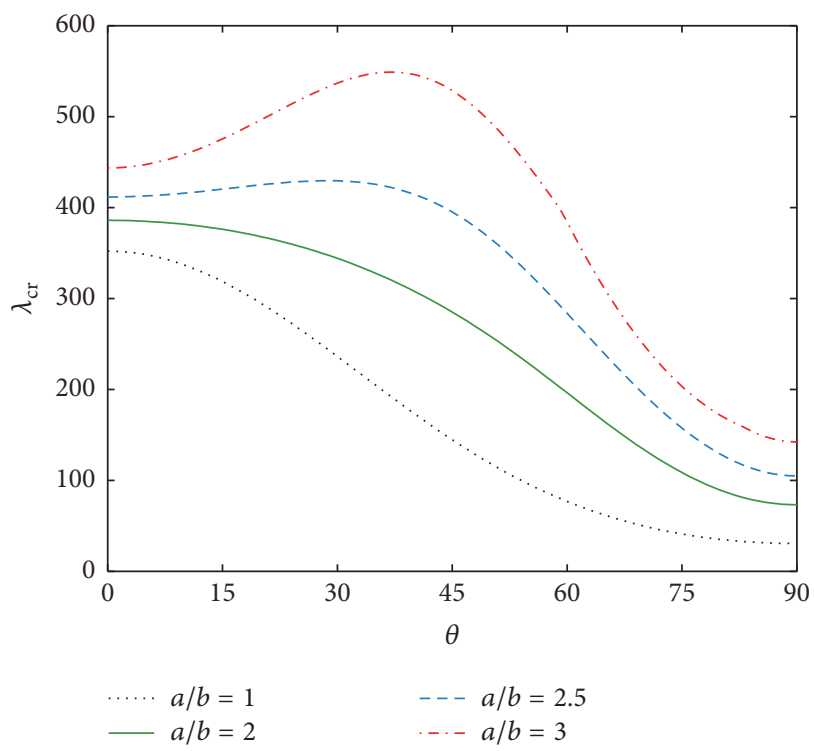

FIGURE 6: Flutter boundary versus layer angle with different lengthto-width ratios.

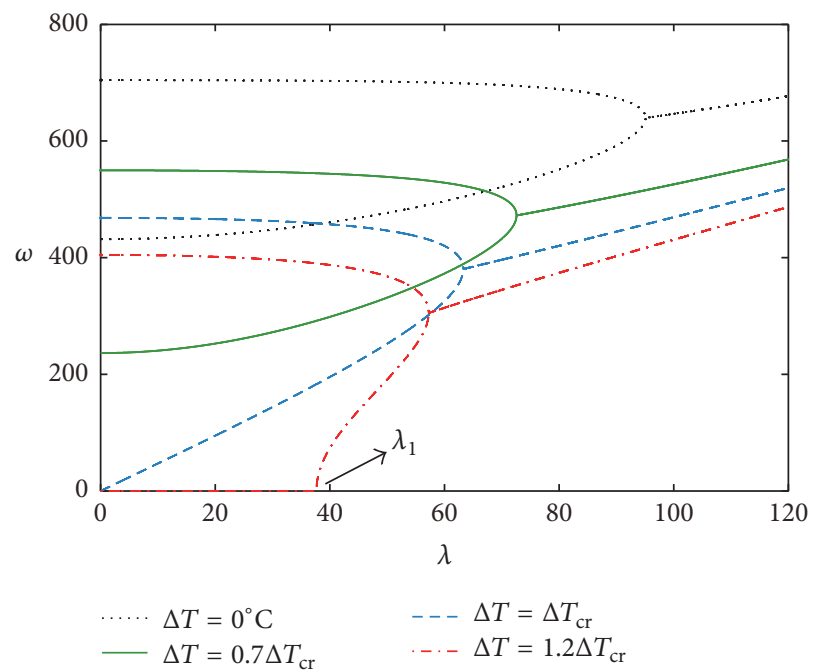

FIGURE 7: Natural frequencies versus dynamic pressure under different temperature variations.

$\lambda_{\text {cr }}$ are reduced with the raise of the temperature variation. When the temperature variation of the panel is raised over the critical buckling temperature $\Delta T_{\mathrm{cr}}$, the panel will be buckling (but dynamically stable) under small dynamic pressure and the first-order natural frequency will be zero. As the dynamic pressure increases up to the critical value $\lambda_{1}$, the motion of the panel will turn to a flat (and stable) condition as shown in Figure 7. So it seems that the process for flutter is contrary to that for thermal buckling.

The curves of frequencies $\omega$ versus $\lambda$ for the panel embedded with/without SMA wires under different temperature variation are shown in Figure 8. The SMA wires have volume fractions of $1 \%$, prestrain of $0.5 \%$, and temperature of $50^{\circ} \mathrm{C}$. It can be revealed from Figure 8 that the panel embedded 


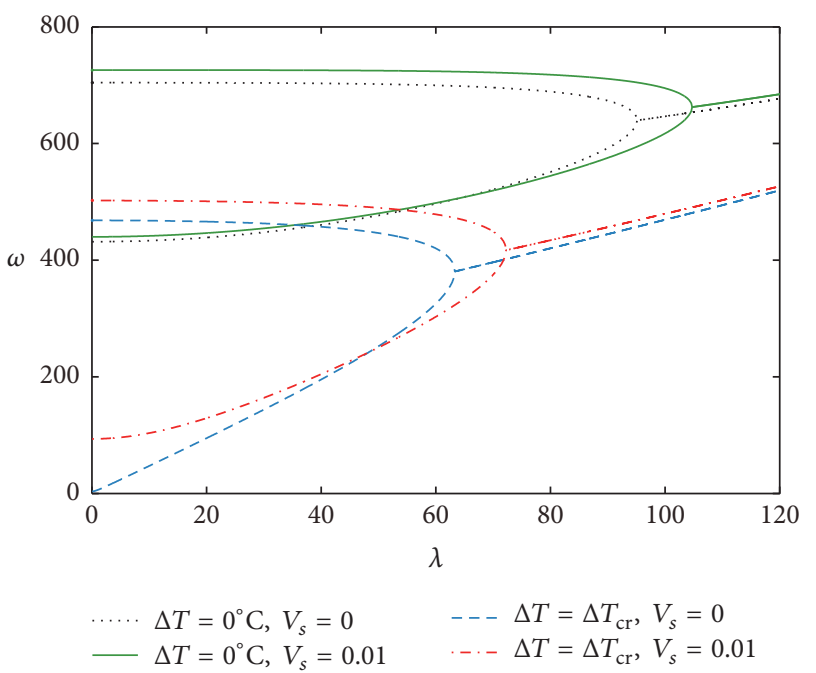

Figure 8: Natural frequencies versus dynamic pressure under different temperature variations and volume fraction of SMA wires.

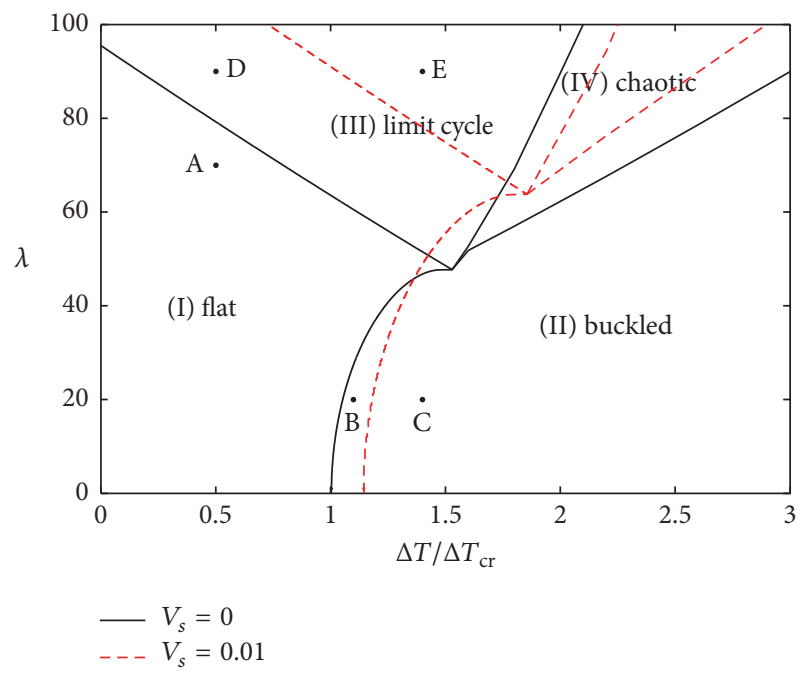

FIGURE 9: Stability margins.

with SMA wires has the same trend as the panel without SMA wires; however, frequencies are enhanced due to the recovery stresses caused by the SMA wires. Moreover, the SMA wires can suppress both the flutter and thermal buckling of the panel.

Figure 9 shows stability margins for the panel embedded with/without SMA wires under combined thermal loads and dynamic pressure load. The SMA wires have volume of fractions of $1 \%$, prestrain of $0.5 \%$, and temperature of $50^{\circ} \mathrm{C}$. The panel has four types of motion: in region (I), under small $\lambda$ and $\Delta T$, the panel is flat and stable; in region (II), for small $\lambda$ and moderate $\Delta T$, thermal buckling occurs; in region (III), for moderate $\lambda$ and $\Delta T$, LCO occurs; in region (IV), for sufficiently high $\lambda$ and $\Delta T$, chaotic motion occurs.

Figures 10-14 present the time history responses of the panel at points A-E in Figure 9, respectively. Figure 10 shows that the transverse vibration of the panel corresponding to

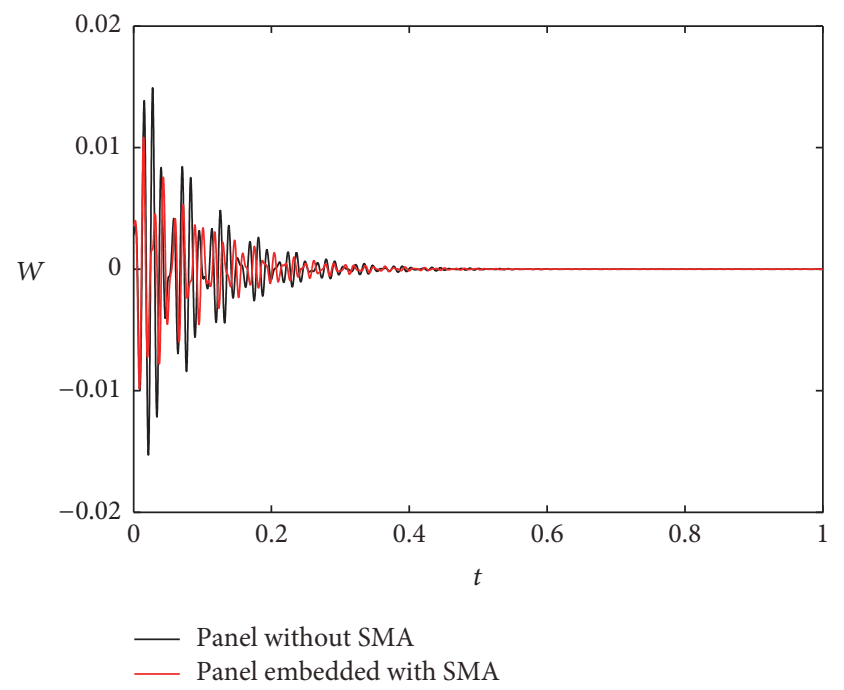

Figure 10: Time history for $\lambda=70$ and $\Delta T=0.5 \Delta T_{\mathrm{cr}}$.

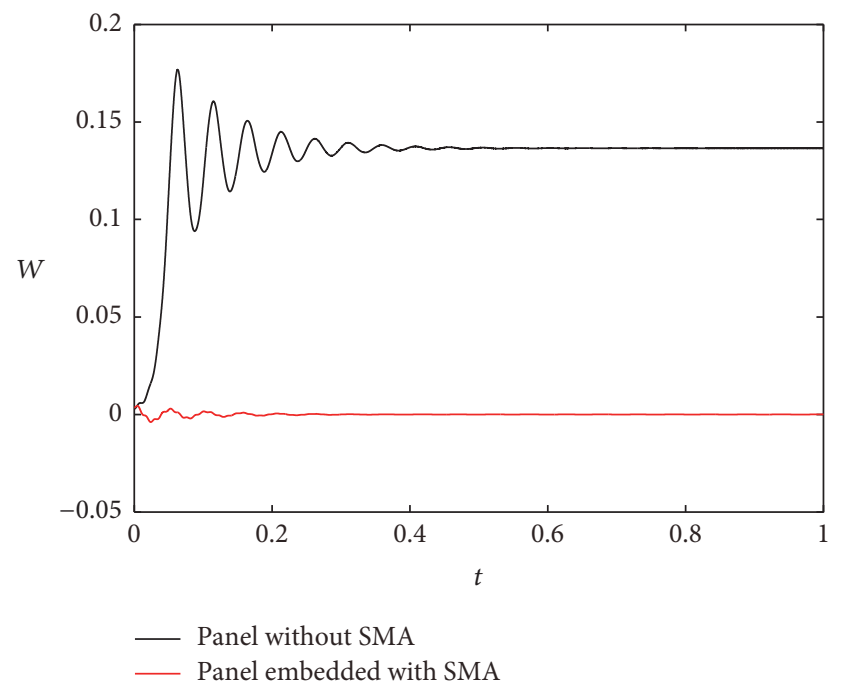

FIgURE 11: Time history for $\lambda=20$ and $\Delta T=1.1 \Delta T_{\mathrm{cr}}$.

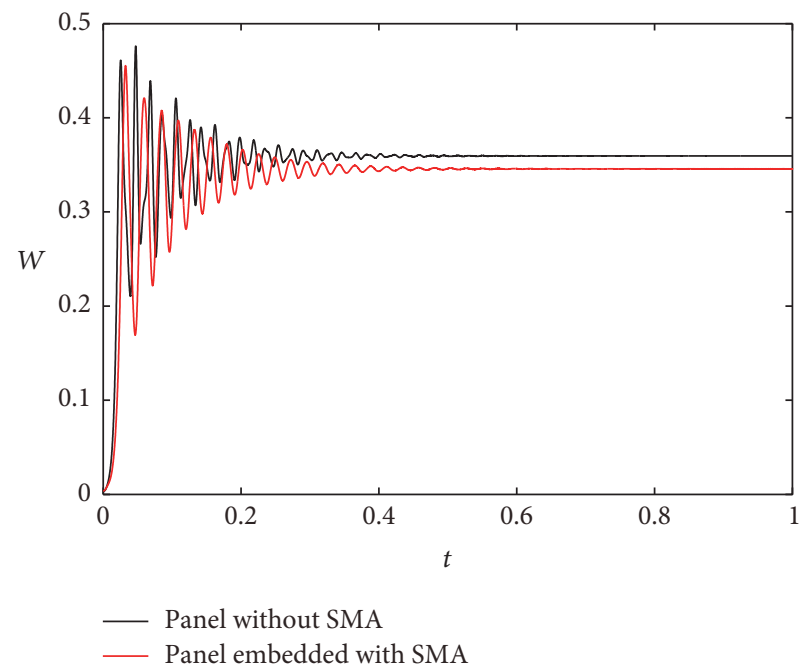

FIGURE 12: Time history for $\lambda=20$ and $\Delta T=1.4 \Delta T_{\text {cr }}$. 


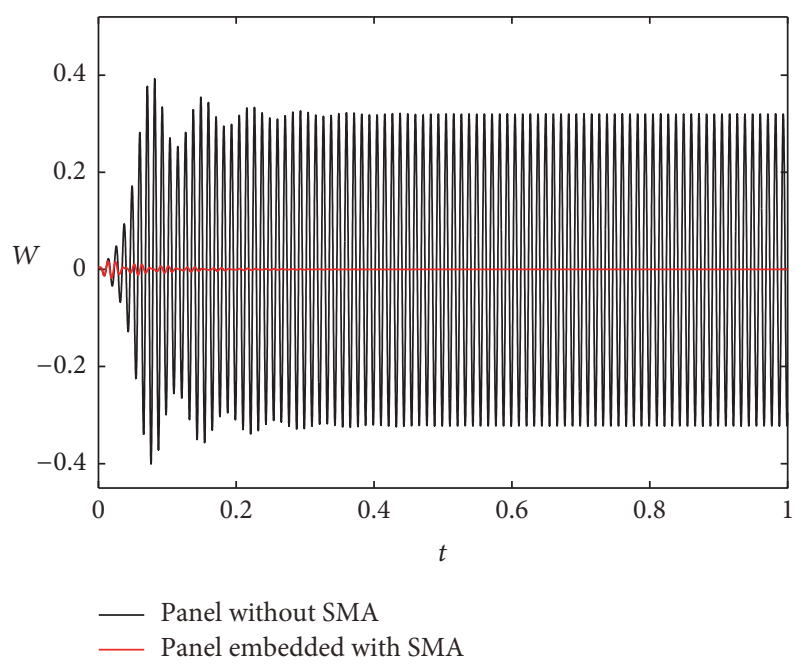

FIGURE 13: Time history for $\lambda=90$ and $\Delta T=0.5 \Delta T_{\mathrm{cr}}$.

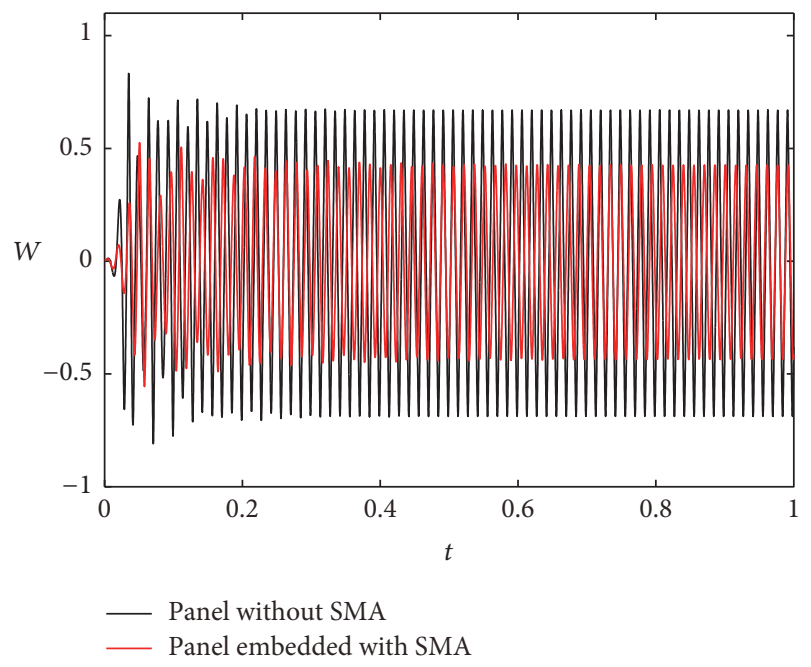

FIGURE 14: Time history for $\lambda=90$ and $\Delta T=1.4 \Delta T_{\mathrm{cr}}$.

point A in district (I) decreases as time increases. Also, the vibration amplitude of the panel embedded with SMA wires converges quickly compared to the panel without SMA wires. The motions of points B and C in Figure 9 are depicted in Figures 11 and 12, respectively. In the case of low dynamic pressure, increasing the temperature variation of the panel above $\Delta T_{\text {cr }}$, the motion will be changed from stable flat to buckled condition. The panel without SMA wires is in a buckled state and the panel embedded with SMA wires is stable flat as shown in Figure 11. Also the buckling deflection of the smart laminated panel is smaller than the conventional laminated panel as observed from Figure 12. Therefore, the SMA wires can suppress the thermal buckling of the panel and reduce the buckling deflection significantly for a given thermal load.

The panel is stable flat at a higher dynamic pressure, and it will flutter as the temperature increased. Figures 13 and 14 plot the motions of points D and E in Figure 9. The panel embedded with SMA wires becomes convergence

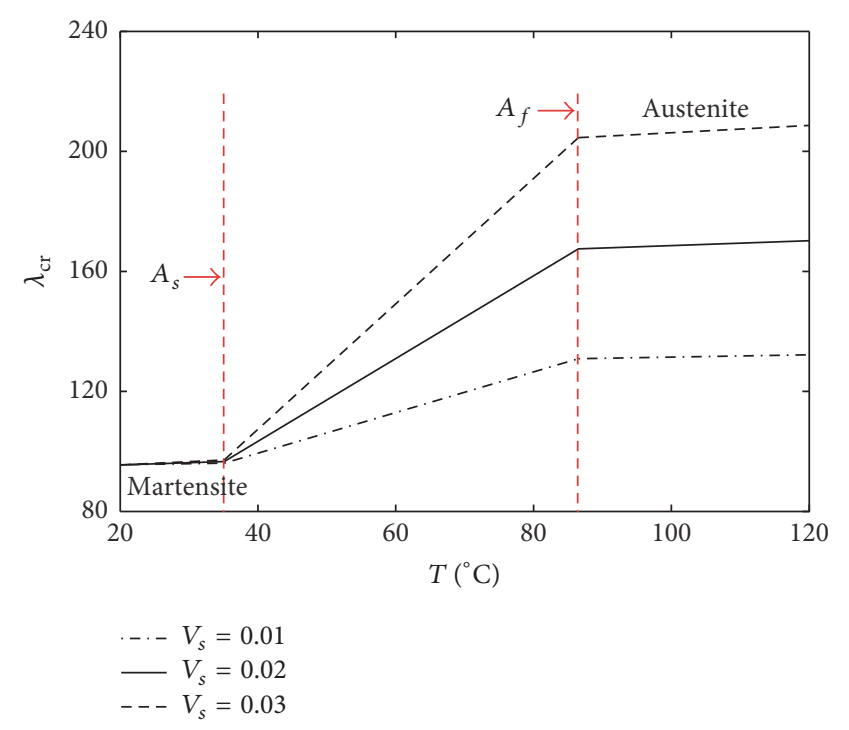

FIgURE 15: Curves of $\lambda_{\text {cr }}$ versus $T$ with various $V_{s}$.

when the panel without SMA wires has LCOs as shown in Figure 13. Also, the amplitude of LCOs of the smart laminated panel is smaller than the conventional laminated panel as observed from Figure 14. As a consequence, the SMA wires can suppress the flutter of the panel and the amplitude of the LCOs can be significantly reduced for a given dynamic pressure.

3.5. The Influences of SMA Wires Temperature, Prestrain, and Volume Fraction. The influences of SMA wires temperature and volume fraction on $\lambda_{\text {cr }}$ are depicted in Figure 15. The SMA wires have prestrain of $0.7 \%$ and the panel temperature variation is assumed to be zero. When the SMA wires temperature is higher than $A_{s}$, phase transformation from martensite to austenite occurs. During this transformation, SMA wires can generate large recovery stress until the temperature is higher than $A_{f}$. Thus $\lambda_{\text {cr }}$ is enhanced via raising the SMA wires temperature as shown in Figure 15. Moreover, as shown in Figure 15, when SMA wires temperature is higher than $A_{s}$, increasing the SMA wires volume fraction leads to an improvement on $\lambda_{c r}$. Thus, for the purpose of enhancing the load-carrying capacity of the smart laminated panel, the parameters of SMA wires must be chosen carefully.

The heated SMA wires can generate recovery stresses and then produce additional stiffness that will change the dynamic response of the panel. SMA wires have prestrain of $0.7 \%$ and temperature of $55^{\circ} \mathrm{C}$. Temperature variation of the panel is assumed to be $1.2 \Delta T_{\mathrm{cr}}$. When the temperature variation is $1.2 \Delta T_{\mathrm{cr}}$, the panel is buckling. With the increase of dynamic pressure, the panel will become stable from the buckling state, and then the flutter will happen as shown in Figures 16 and 17. It is shown from Figure 16 that raising the volume fraction is able to enhance the stability margin of the panel. Figure 17 demonstrates the buckling deflection and amplitude of LCO versus dynamic pressure with different volume fractions of SMA wires. As displayed, using SMA wires can reduce both the buckling deflection 


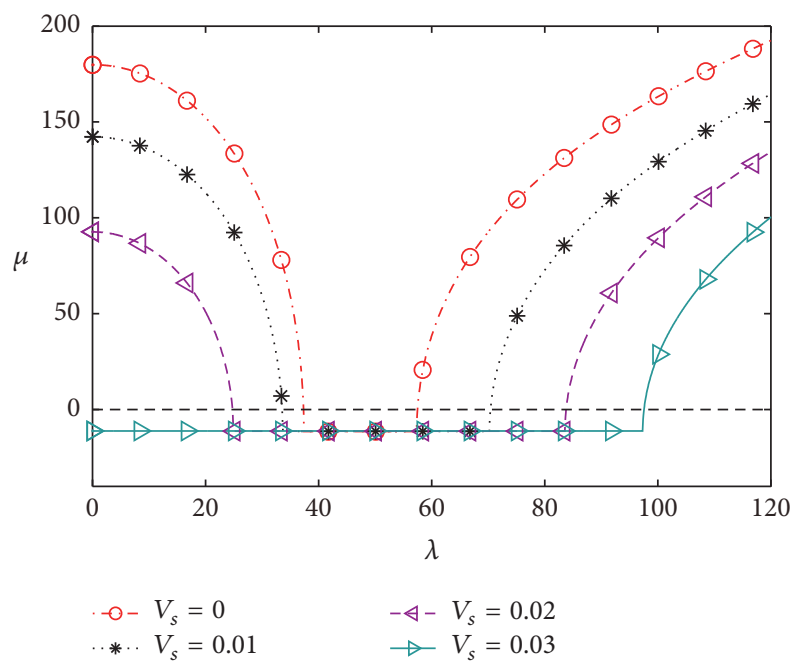

FIGURE 16: Influence of $V_{s}$ on stability boundary.

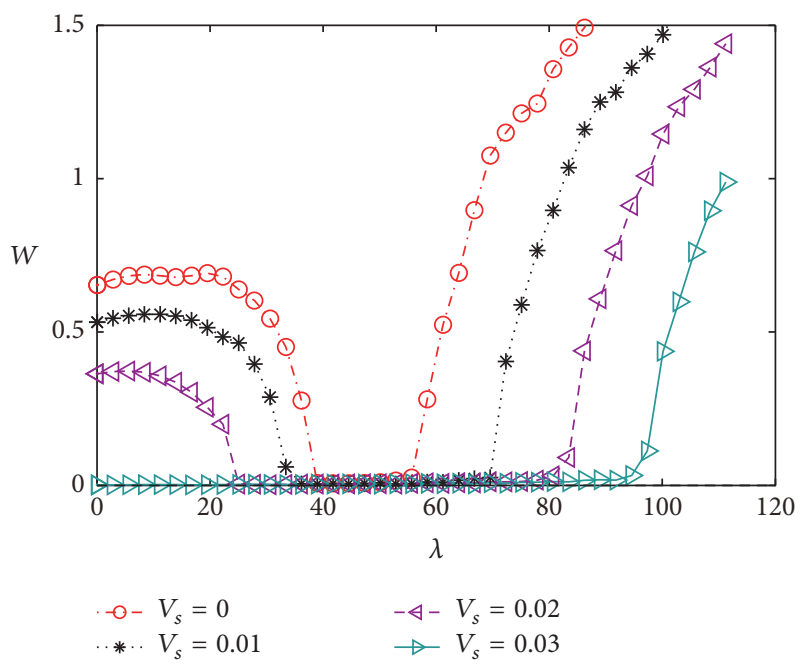

FIGURE 17: Influence of $V_{s}$ on buckling, flat, and flutter phenomena.

and the amplitude of LCO. The results clearly indicate that the recovery stress introduced by SMA wires leads to a more stiffened panel for a wide range of dynamic pressure and thus a higher critical flutter dynamic pressure. Specifically, for a higher volume fraction as $V_{s}=0.03$, the buckling of the panel will not happen for a temperature variation $1.2 \Delta T_{\mathrm{cr}}$.

Figures 18 and 19 reveal the influences of SMA wires temperature on $\Delta T_{\mathrm{cr}}, \lambda_{\mathrm{cr}}$, and transverse vibration of the panel. The temperature variation of the panel is assumed to be $1.2 \Delta T_{\mathrm{cr}}$ and the SMA wires have prestrain of $1 \%$ and volume fraction of 0.01. As shown in Figure 18, $\Delta T_{\mathrm{cr}}$ and $\lambda_{\mathrm{cr}}$ increase with raising the SMA wires temperature. Also, as displayed in Figure 19, the amplitude of LCO can be reduced by increasing the SMA wires temperature.

The influence of prestrain on the buckling and flutter behavior of the panel is displayed in Figures 20 and 21. The temperature variation of the panel is assumed to be

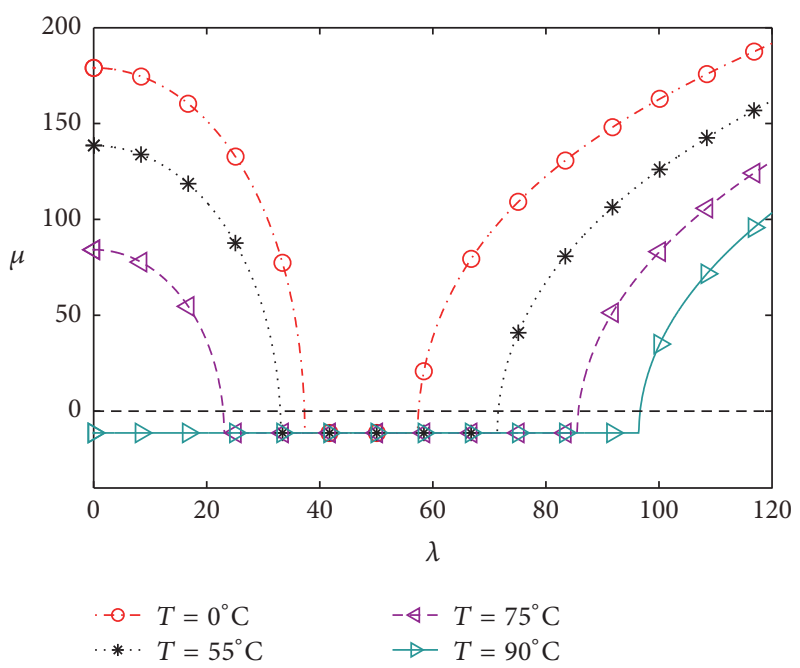

FIGURE 18: Influence of $T$ on stability boundary.

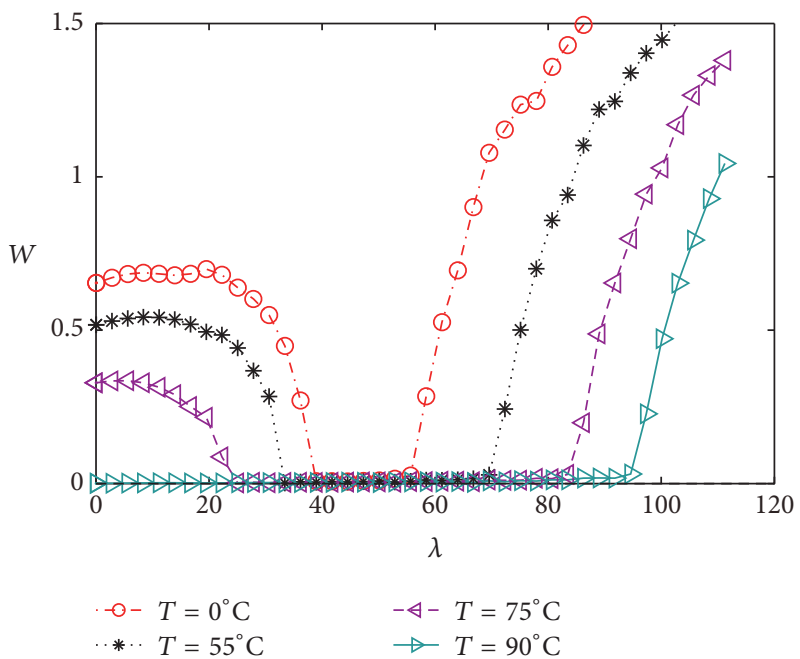

FIgURE 19: Influence of $T$ on buckling, flat, and flutter phenomena.

$1.2 \Delta T_{\mathrm{cr}}$ and the SMA wires have volume fraction of 0.01 and temperature of $90^{\circ} \mathrm{C}$. Raising the SMA wires prestrain can augment equal stiffness of the panel and therefore $\lambda_{\text {cr }}$ and $\Delta T_{\mathrm{cr}}$ are increased as demonstrated in Figure 20. Figure 21 demonstrates the influence of prestrain on the buckling deflection and amplitude of LCO of the panel. It can be concluded that the buckling deflection and amplitude of LCO can be alleviated by increasing the SMA wires prestrain.

\section{Conclusions}

Thermal buckling and flutter behaviors of a laminated composite panel embedded with SMA wires subjected to nonlinear aerodynamic loading and thermal load have been analyzed in this paper. The von-Karman large deflection plate theory for structures, one-dimensional Brinson model for 


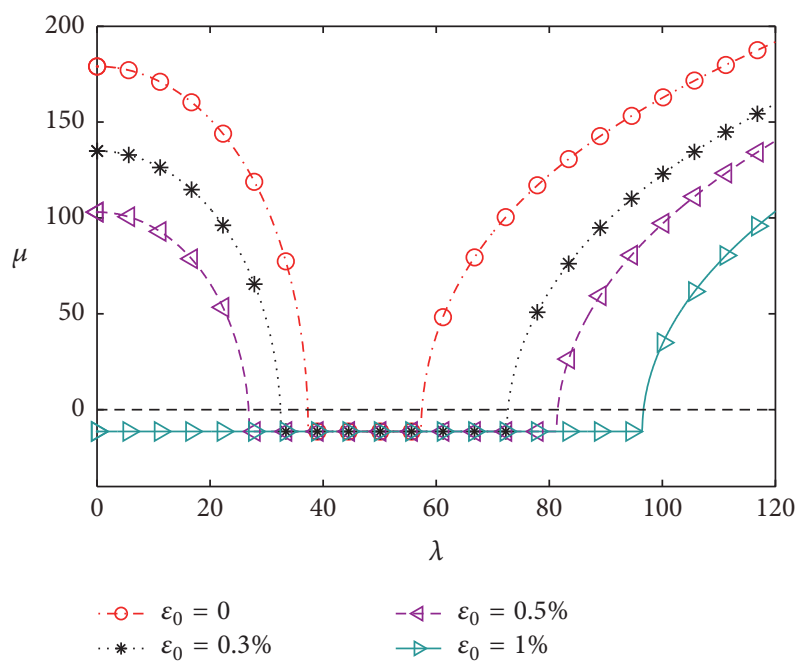

FIGURE 20: Influence of $\varepsilon_{0}$ on stability boundary.

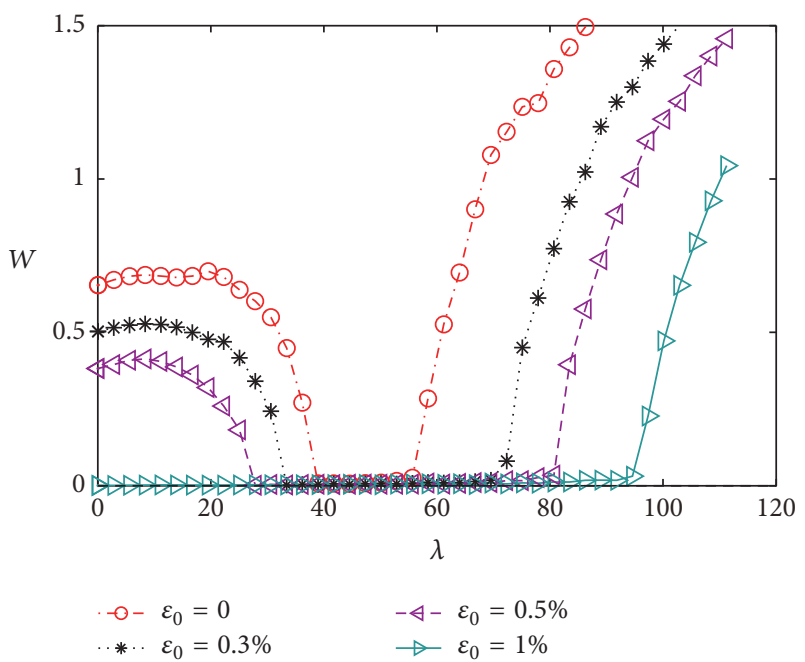

FIGURE 21: Influence of $\varepsilon_{0}$ on buckling, flat, and flutter phenomena.

SMA wires, and the nonlinear piston theory for aerodynamics are used to derive the nonlinear governing equation of motion for the panel embedded with SMA wires. The system discrete dynamic model is obtained by employing the Galerkin method. A composite panel with a set of typical material constants and geometrical parameters is taken as an example to illustrate the method proposed in this study. The Runge-Kutta method has been employed to solve the system. The numerical results show the following:

(1) When $a / b$ is lower than 2 , the aeroelastic stability of laminated panel is decreasing with the increase of the ply angle $[\theta /-\theta / \theta /-\theta]_{s}$; however, when $a / b$ is more than 2 , the aeroelastic stability will increase as the ply angle increases initially and decrease afterwards.

(2) Embedding SMA wires in the layers of composite panel can improve the aeroelastic stability boundary, and the most efficient design is to embed SMA wires in the airflow direction.
(3) It is more significant to embed SMA wires in the outer layer of the laminated panel than in the inner layer for the flutter characteristics.

(4) The critical flutter dynamic pressure and critical thermal buckling temperature can be enhanced by heating the SMA wires, increasing SMA wires volume fraction or prestrain. Therefore, the critical flutter dynamic pressure and critical thermal buckling temperature of the smart laminated panel can be greatly increased and the amplitude of LCO can be significantly reduced for a given flutter dynamic pressure.

The theoretical results presented in this paper can be applied in the practical engineering problem involving shape memory alloy wires. It is helpful for the aeroelastic analysis and vibration control of supersonic structures.

\section{Nomenclature}

\section{(A) Composite Parameters}

a: $\quad$ Length of the panel

$b$ : Width of the panel

$D_{11}^{(0)}$ : $\quad$ Value of the mass moment of inertia of the panel when all fibers are aligned with the $x$-axis

$E_{1 m}, E_{2 m}$ : Young modulus of matrix in 1 and 2 directions

$E_{s}: \quad$ Young modulus of SMA wire

$h$ : Thickness of the composite panel

M: $\quad$ Mach number

$M_{k l}, N_{k l}$ : Force resultants operators

$q$ : $\quad$ Dynamic pressure

Q: $\quad$ Lamina stiffness matrix

$u, v, w$ : Displacements of the panel in the $x, y, z$ directions

$u_{0}, v_{0}, w_{0}$ : Displacements of the midplane

$V_{m}: \quad$ Volume fractions of the matrix

$W: \quad$ Transverse vibration amplitude

$v_{\infty}$ : Relative free airstream velocity

$\Delta p: \quad$ Aerodynamic pressure

$\Delta T: \quad$ Panel temperature variation

$\delta T: \quad$ Virtual kinetic energy

$\delta U: \quad$ Virtual strains energy

$\delta W: \quad$ Virtual work done by the aerodynamic pressure

$\varphi_{j}: \quad$ Eigen values of a matrix $A$

$\lambda: \quad$ Dimensionless dynamic $\left(=2 q a^{3} / M D_{11}^{(0)}\right)$

$\mu: \quad$ The maximum real part of $\varphi$

$\rho_{m}, \rho_{s}: \quad$ Density of the matrix and SMA wires

$v_{12 m}, v_{s}$ : Poisson ratio of matrix and SMA wires

$\omega: \quad$ Panel natural frequency.

(B) SMA Brinson Model Parameters

$\sigma_{r}$ : Recovery stress of SMA

$\Theta$ : Thermoelastic modulus 
$E_{M}: \quad$ Martensite Young modulus

$E_{A}$ : Austenite Young modulus

$\varepsilon_{L}: \quad$ Maximum residual strain

$\varepsilon_{0}: \quad$ Prestrain

$M_{f}$ : Martensite finish temperature

$M_{s}$ : $\quad$ Martensite start temperature

$A_{s}: \quad$ Austenite start temperature

$A_{f}$ : Austenite finish temperature

$c_{A}, c_{M}$ : Stress influence coefficient

$\xi$ : $\quad$ Total martensite volume fraction

$\xi_{s}: \quad$ Stress induced martensite volume fraction

$\xi_{s 0}: \quad$ Initial stress induced martensite volume fraction

$\xi_{T}: \quad$ Temperature induced martensite volume fraction

$\xi_{T 0}: \quad$ Initial temperature induced martensite volume fraction.

\section{Competing Interests}

The authors declare that they have no competing interests.

\section{Acknowledgments}

The authors gratefully acknowledge the National Natural Science Foundation of China (Grant no. 91216106) for the financial support of this work.

\section{References}

[1] E. H. Dowell, "Nonlinear oscillations of a fluttering plate," The American Institute of Aeronautics and Astronautics, vol. 4, no. 7, pp. 1267-1275, 1966.

[2] E. H. Dowell, "Panel flutter, a review of the aeroelastic stability of plates and shells," AIAA Journal, vol. 8, no. 3, pp. 385-399, 1970.

[3] C. Mei, K. Abdel-Motagaly, and R. Chen, "Review of nonlinear panel flutter at supersonic and hypersonic speeds," Applied Mechanics Reviews, vol. 52, no. 10, pp. 321-332, 1999.

[4] V. Birman and L. Librescu, "Supersonic flutter of shear deformable laminated composite flat panels," Journal of Sound and Vibration, vol. 139, no. 2, pp. 265-275, 1990.

[5] M. A. Kouchakzadeh, M. Rasekh, and H. Haddadpour, "Panel flutter analysis of general laminated composite plates," Composite Structures, vol. 92, no. 12, pp. 2906-2915, 2010.

[6] H. Zhao and D. Cao, "A study on the aero-elastic flutter of stiffened laminated composite panel in the supersonic flow," Journal of Sound and Vibration, vol. 332, no. 19, pp. 4668-4679, 2013.

[7] J. F. Abbas, R. A. Ibrahim, and R. F. Gibson, "Nonlinear flutter of orthotropic composite panel under aerodynamic heating," AIAA Journal, vol. 31, no. 8, pp. 1478-1488, 1993.

[8] L.-C. Shiau, S.-Y. Kuo, and Y.-P. Liu, "Aerothermoelastic analysis of composite laminated plates," Composite Structures, vol. 94, no. 6, pp. 1982-1990, 2012.

[9] D. Xie, M. Xu, H. Dai, and E. H. Dowell, "Proper orthogonal decomposition method for analysis of nonlinear panel flutter with thermal effects in supersonic flow," Journal of Sound and Vibration, vol. 337, pp. 263-283, 2015.
[10] D. Y. Xue and C. Mei, "Finite element nonlinear panel flutter with arbitrary temperatures in supersonic flow," AIAA journal, vol. 31, no. 1, pp. 154-162, 1993.

[11] F.-M. Li and Z.-G. Song, "Flutter and thermal buckling control for composite laminated panels in supersonic flow," Journal of Sound and Vibration, vol. 332, no. 22, pp. 5678-5695, 2013.

[12] V. Birman, "Review of mechanics of shape memory alloy structures," Applied Mechanics Reviews, vol. 50, no. 11, pp. 629645, 1997.

[13] J.-S. Park, J.-H. Kim, and S.-H. Moon, "Thermal post-buckling and flutter characteristics of composite plates embedded with shape memory alloy fibers," Composites Part B: Engineering, vol. 36, no. 8, pp. 627-636, 2005.

[14] W. Ostachowicz, M. Krawczuk, and A. Żak, "Dynamics and buckling of a multilayer composite plate with embedded SMA wires," Composite Structures, vol. 48, no. 1-3, pp. 163-167, 2000.

[15] M. M. Barzegari, M. Dardel, A. Fathi, and M. Ghadimi, "Aeroelastic characteristics of cantilever wing with embedded shape memory alloys," Acta Astronautica, vol. 79, pp. 189-202, 2012.

[16] H. Asadi, M. Bodaghi, M. Shakeri, and M. M. Aghdam, "An analytical approach for nonlinear vibration and thermal stability of shape memory alloy hybrid laminated composite beams," European Journal of Mechanics A-Solids, vol. 42, pp. 454-468, 2013.

[17] S.-Y. Kuo, L.-C. Shiau, and C.-H. Lai, "Flutter of buckled shape memory alloy reinforced laminates," Smart Materials and Structures, vol. 21, no. 3, Article ID 035020, 2012.

[18] H. H. Ibrahim, M. Tawfik, and H. M. Negm, "Thermal buckling and nonlinear flutter behavior of shape memory alloy hybrid composite plates," Journal of Vibration and Control, vol. 17, no. 3, pp. 321-333, 2011.

[19] X. Zhao, Y. Y. Lee, and K. M. Liew, "Mechanical and thermal buckling analysis of functionally graded plates," Composite Structures, vol. 90, no. 2, pp. 161-171, 2009.

[20] L.-C. Shiau, S.-Y. Kuo, and C.-Y. Chen, "Thermal buckling behavior of composite laminated plates," Composite Structures, vol. 92, no. 2, pp. 508-514, 2010.

[21] Y. Shi, R. Y. Y. Lee, and C. Mei, “Thermal postbuckling of composite plates using the finite element modal coordinate method," Journal of Thermal Stresses, vol. 22, no. 6, pp. 595-614, 1999.

[22] H. Matsunaga, "Thermal buckling of cross-ply laminated composite and sandwich plates according to a global higher-order deformation theory," Composite Structures, vol. 68, no. 4, pp. 439-454, 2005.

[23] V. Birman, Plate Structures (Solid Mechanics and Its Applications), Springer, New York, NY, USA, 2011.

[24] L. C. Brinson, "One-dimensional constitutive behavior of shape memory alloys: thermomechanical derivation with nonconstant material functions and redefined martensite internal variable," Journal of Intelligent Material Systems and Structures, vol. 4, no. 2, pp. 229-242, 1993.

[25] E. H. Dowell, "Nonlinear oscillations of a fluttering plate. II," AIAA Journal, vol. 5, no. 10, pp. 1856-1862, 1967.

[26] D. Y. Xue and C. Mei, "Finite element nonlinear flutter and fatigue life of two-dimensional panels with temperature effects," Journal of Aircraft, vol. 30, no. 6, pp. 993-1000, 1993. 


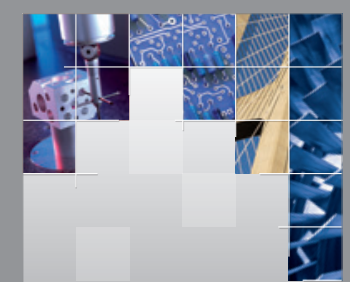

\section{Enfincering}
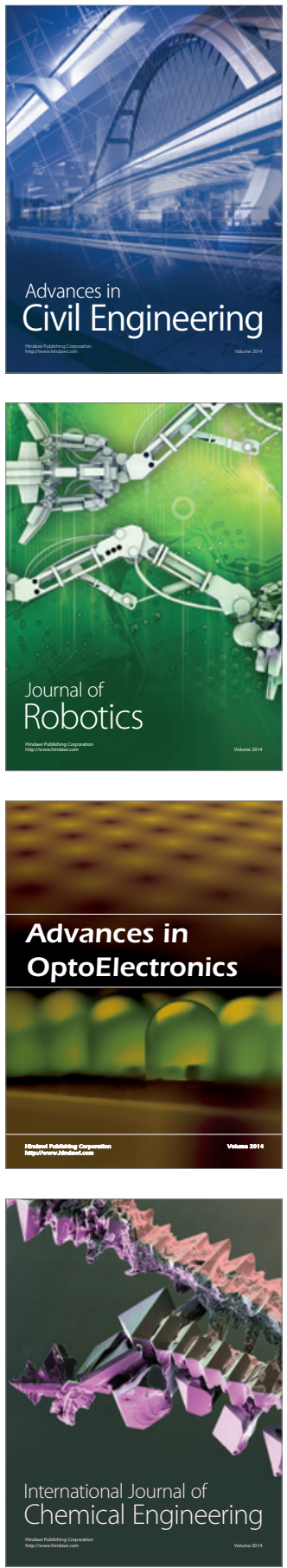

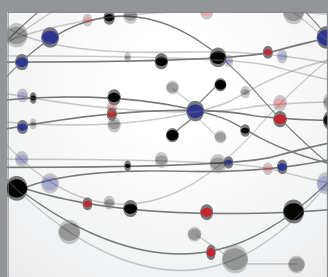

The Scientific World Journal

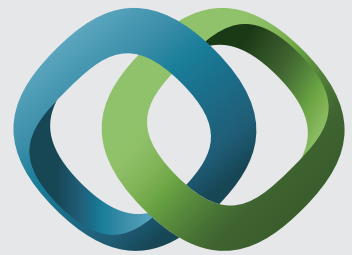

\section{Hindawi}

Submit your manuscripts at

http://www.hindawi.com
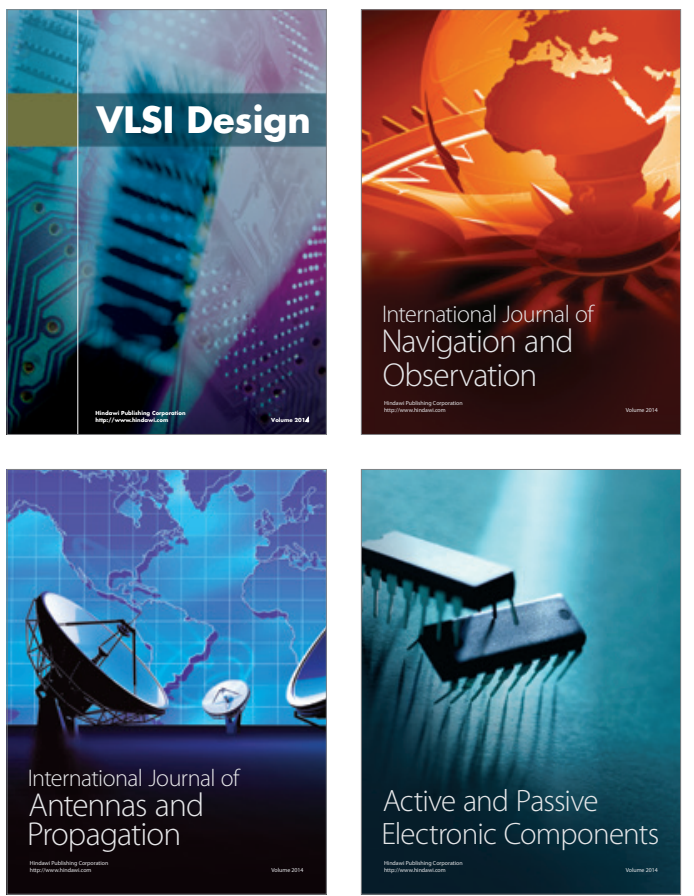
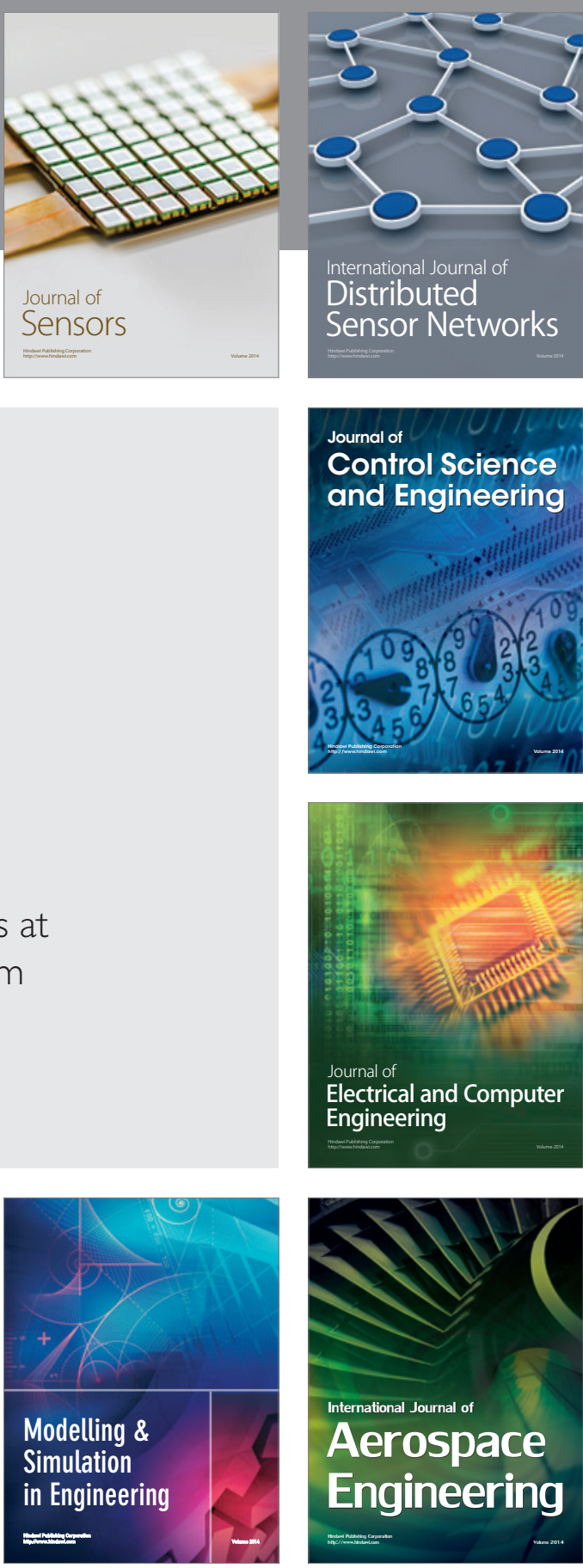

International Journal of

Distributed

Sensor Networks

Journal of

Control Science

and Engineering
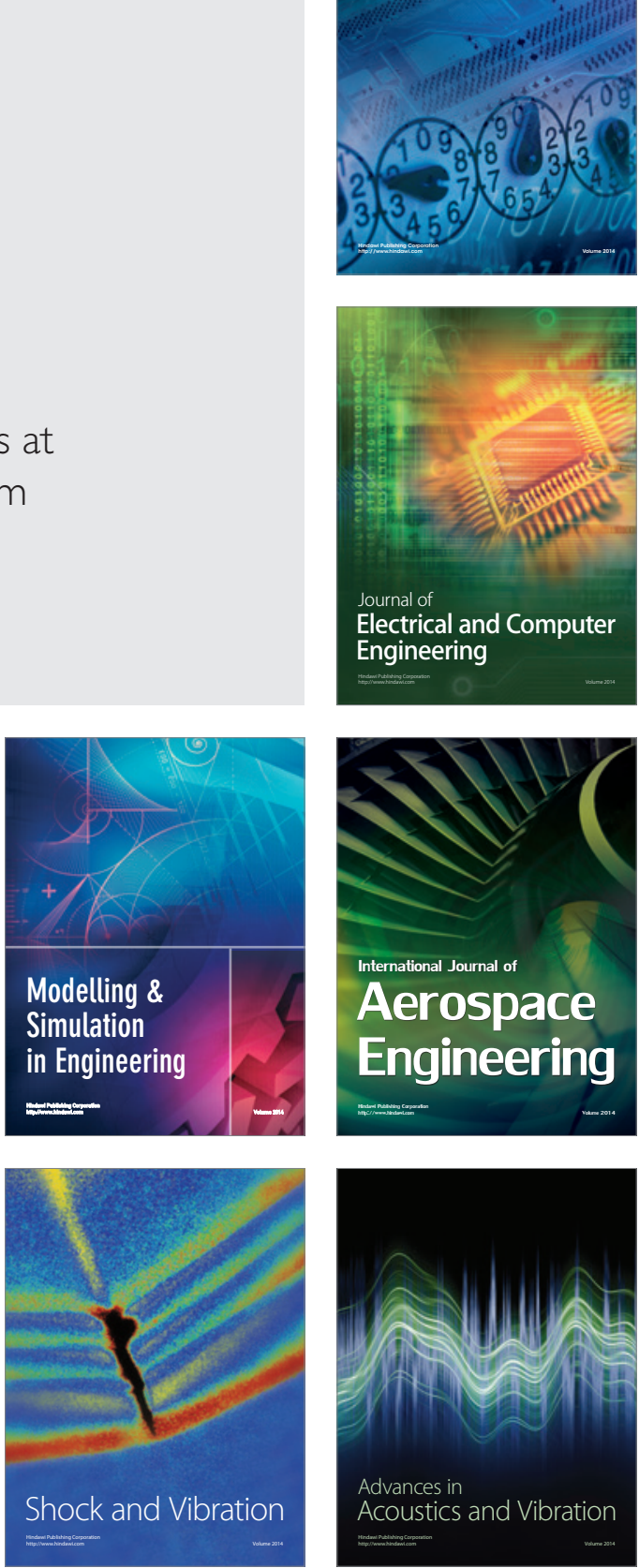